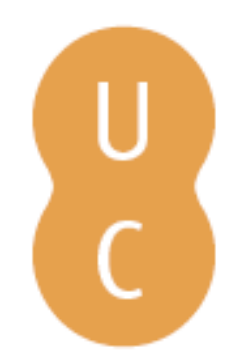

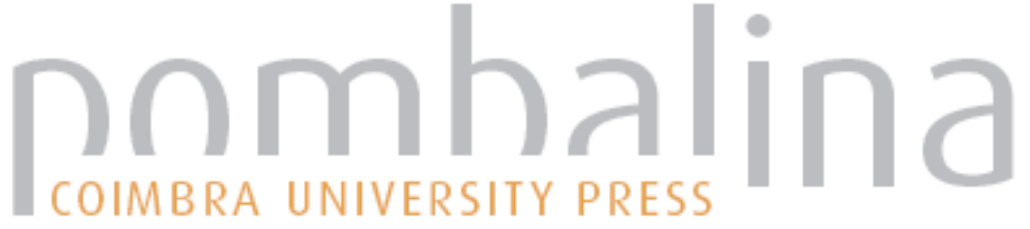

\section{Os SIG na fiscalidade municipal: aplicação ao cálculo e gestão da TRMIU}

\author{
Autor(es): $\quad$ Deus, Raquel de \\ Publicado por: Imprensa da Universidade de Coimbra \\ URL \\ persistente: URI:http://hdl.handle.net/10316.2/31177 \\ DOI: $\quad$ DOI:http://dx.doi.org/10.14195/978-989-26-0244-8_79 \\ Accessed : $\quad$ 26-Apr-2023 16:24:39
}

A navegação consulta e descarregamento dos títulos inseridos nas Bibliotecas Digitais UC Digitalis, UC Pombalina e UC Impactum, pressupõem a aceitação plena e sem reservas dos Termos e Condições de Uso destas Bibliotecas Digitais, disponíveis em https://digitalis.uc.pt/pt-pt/termos.

Conforme exposto nos referidos Termos e Condições de Uso, o descarregamento de títulos de acesso restrito requer uma licença válida de autorização devendo o utilizador aceder ao(s) documento(s) a partir de um endereço de IP da instituição detentora da supramencionada licença.

Ao utilizador é apenas permitido o descarregamento para uso pessoal, pelo que o emprego do(s) título(s) descarregado(s) para outro fim, designadamente comercial, carece de autorização do respetivo autor ou editor da obra.

Na medida em que todas as obras da UC Digitalis se encontram protegidas pelo Código do Direito de Autor e Direitos Conexos e demais legislação aplicável, toda a cópia, parcial ou total, deste documento, nos casos em que é legalmente admitida, deverá conter ou fazer-se acompanhar por este aviso.

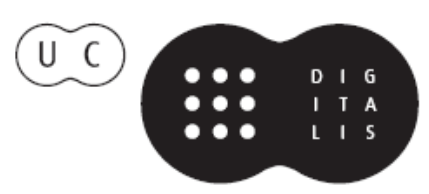




\section{TRUNFOS DE UMA}

\section{EOGRAFIA ACIVA}

\section{DESENVOLVIMENTO LOCAL,}

AMBIENTE,

ORDENAMENTO

E TECNOLOGIA

Norberto Santos

Lúcio Cunha

COORDENAÇÃO 
Raquel de Deus

Departamento Técnico de Planeamento e Urbanismo, Câmara Municipal de Portimáo

\author{
OS SIG NA FISCALIDADE MUNICIPAL \\ APLICAÇÃO AO CÁLCULO E GESTÃO DA TRMIU ${ }^{1}$
}

\title{
1.INTRODUÇÃO
}

A correcta aplicação de instrumentos fiscais municipais e a sua boa colecta são meios de financiamento importantes que podem contribuir para a maior autonomia dos municípios, reforçando a sua capacidade de gestão financeira dos interesses específicos das populaçôes locais.

A importância do montante da colecta da TMU tem vindo a crescer e a tornar-se fundamental no âmbito geral do reforço da autonomia local através do incremento dos poderes tributários dos municípios, adoptado pela nova Lei das Finanças Locais - Lei n. ${ }^{\circ}$ 2/2007, de 15 de Janeiro.

A TMU é um dos vários instrumentos fiscais de política de solos ao dispor dos municípios, cujo objectivo consiste em fazer recair os encargos resultantes da produção de tecidos urbanizados nos agentes que os produzem dotando os municípios das receitas necessárias ao financiamento dos investimentos em infra-estruturas induzidas pela urbanização. A aplicação dos SIG ao cálculo e gestáo da TMU apresenta-se obrigatoriamente como campo de actuação de futuro, face à inevitável necessidade de modernização e de aumento de capacidade de resposta perante a publicaçáo da Lei n. ${ }^{\circ}$ 53-E/2006 (aprova o regime geral das taxas das autarquias locais), de 29 de Dezembro.

Deste modo, os municípios obterão claros benefícios se se dotarem com ferramentas que proporcionem automatismos que permitam uma mais eficaz gestão da informação sobre o território e adoptem procedimentos de maior eficiência e transparência, nos instrumentos fiscais a seu cargo e mais ligados à prestação de serviços à população como é o caso da TMU.

\section{A Fiscalidade do Urbanismo - A TAXa Municipal de URbanizaÇão ENQUANTO FIGURA TRIBUTÁRIA}

A lógica da tributação sobre o urbanismo passa pela garantia dos meios de financiamento das necessidades públicas induzidas pela actividade urbanística e pela sua utilização como

\footnotetext{
${ }^{1}$ Dissertação apresentada em Dezembro de 2008, para obtenção do Grau de Mestre em Sistemas de Informação Geográfica, pelo Instituto Superior Técnico da Universidade Técnica de Lisboa, sob orientação do Professor Doutor Jorge Manuel Lopes Baptista e Silva.
} 
instrumento urbanístico com consequências sobre o processo de ocupação do território e num âmbito geral, pela conciliação de um sistema urbanístico eficiente, visando o Bem-Estar Social (Baptista Lobo 2006).

A taxa pela realização e manutenção de infra-estruturas urbanísticas primárias e secundárias $^{2}$ - TRMIU (também designada por Taxa Municipal de Urbanização - abreviada por TMU), foi introduzida em Portugal no ano de 1984, no âmbito da aprovaçáo da Lei das Finanças Locais, Lei n. ${ }^{\circ}$ 98/84, de 29 de Março. O propósito que norteou a criação deste instrumento de tributação fiscal foi o facto de já durante as décadas de sessenta e setenta, se ter verificado um intenso desenvolvimento urbanístico. Daí que o intuito deste tributo fosse o de assegurar o financiamento que viabilizasse a disponibilização das infraestruturas e equipamentos necessários a um desenvolvimento urbano equilibrado, promovendo-se a sustentabilidade financeira dos governos locais e o reforço da sua autonomia.

No entanto, a capacidade de concretização destes investimentos por parte da administração municipal, está fortemente dependente da adequação dos valores das taxas à realidade dos custos actuais e previstos quer em termos de investimento quer em termos de gestão e conservação das redes de infra-estruturas urbanas (Correia 2001). A determinação dos valores da taxa a aplicar deverá fundamentar-se no cálculo do investimento necessário à execução dos serviços municipais disponibilizados ou a disponibilizar, baseado em critérios de decisão política, garantindo-se, em simultâneo a equidade na distribuiçáo dos encargos públicos de infraestruturação pelos proprietários directamente beneficiados e a auto-suficiência financeira dos governos locais (Sá 2005). A correcta aplicação da TMU, assim como a concepção da sua fórmula de cálculo, exigem que se tenha uma noção precisa das infra-estruturas urbanísticas. Adoptando uma perspectiva abrangente, as infra-estruturas urbanísticas podem ser diferenciadas quanto à sua incidência no território e às necessidades que prestam. Deste modo, existirão: i) infra-estruturas urbanísticas locais, constituídas pelas infra-estruturas que beneficiam apenas um determinado sub-espaço concelhio e ii) infra-estruturas urbanísticas gerais, que favorecem a totalidade do concelho e relativamente às quais não é possível determinar áreas mais beneficiadas em detrimento de outras.

\section{DE QUE FORMA OS SIG PODEM SER UMA FERRAMENTA NO DOMÍNIO DA FISCALIDADE MUNICIPAL E EM PARTICULAR, NA DEFINIÇÃO E GESTÃO DE UMA TMU?}

A garantia de igualdade de tratamento de todos os indivíduos perante as actuaçóes dos poderes públicos, requer a montagem de sistemas de informação de fácil acesso, quer em termos da sua compreensão como da sua divulgaçáo. Os SIG devem visar apoiar o processo de planeamento, seja na elaboração seja na divulgação de regras e resultados. Afinal, a transparência deve ser um dos princípios norteadores de qualquer administração democrática. Com a importância que a TMU têm vindo a assumir no âmbito das receitas municipais e consequentemente no desenvolvimento e planeamento urbano, os recentes desenvolvimentos nos SIG e na tecnologia de informação relacionada, podem proporcionar novas oportunidades para os governos locais estudarem e monitorizem o impacte desta taxa no desenvolvimento municipal (Moudon \& Hubner 2000).

\footnotetext{
${ }^{2}$ Designação utilizada pela Lei das Finanças Locais, Lei n. ${ }^{\circ}$ 2/2007, de 15 de Janeiro.
} 
A integração dos SIG na Fiscalidade Municipal representa uma maior facilidade para as decisóes autárquicas no que respeita à flexibilidade necessária para os desafios que, constantemente se colocam no desempenho, na qualidade da gestão e na operacionalidade dos serviços. Concorre-se, assim, para a introdução de novas tecnologias na Administração Local, como instrumentos que eliminam passos desnecessários, conduzem a reorganizaçóes internas que tornam mais acessível a informação, clarificam e promovem a eficiência nos procedimentos e facilitam o acesso do munícipe à informação mais relevante. Os benefícios da utilização dos SIG no cálculo e gestão de uma TMU são particularmente perceptíveis no apoio à definiçáo de um zonamento com o intuito de se diferenciar espacialmente a TMU e no desenvolvimento de uma ferramenta que permitiu a automatização de tarefas correntes no âmbito da fixação da TMU. Possibilita-se, deste modo, a readequação dos dispositivos legais e tributários, sobretudo, na obtenção de justiça fiscal e tributária no uso do solo, que passa a ser mapeado de forma sistemática e precisa.

\section{Sistema de INFORMAÇÃo GEOGRÁFICA PARA IMPLEMENTAÇÃO DA TAXA A APLICAR PELA REALIZAÇÃO DE INFRA-ESTRUTURAS URBANÍSTICAS MUNICIPAIS}

\subsection{Aplicação ao caso de estudo: Município de Aljezur}

O território em análise abrange toda a área do município de Aljezur, incluindo as suas quatro freguesias, distribuídas por uma área de $322,6 \mathrm{~km}^{2}$ (Figura 1).

Figura 1 - Localização da área de estudo.

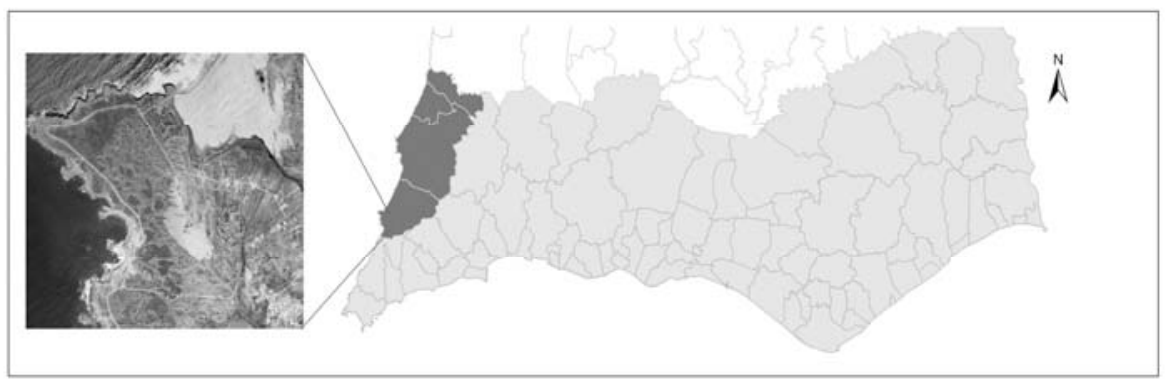

Situado numa área abrangida pelo Parque Natural do Sudoeste Alentejano e Costa Vicentina - caracterizada por paisagens marcadas por uma elevada qualidade cénica e ecológica, ainda existem áreas edificadas desqualificadas e clandestinas. Esta situaçáo acaba por se repercutir na carência em infra-estruturas urbanísticas e em especial, numa completa descaracterização do tecido urbano construído. O povoamento caracteriza-se pela baixa densidade, a que se associa uma população envelhecida e com baixos níveis de escolaridade. A tendência para o progressivo envelhecimento da população do concelho, para além de representar um grave problema demográfico, justifica uma reavaliação do nível de carência em infra-estruturas urbanísticas. Esta regiáo é no entanto um exemplo paradigmático da vincada dicotomia Litoral/Interior e Urbano/Rural. Trata-se de uma área rural 
deprimida numa região dinâmica, onde a pressão urbanística é iminente, ampliando assim o interesse de investigação, tanto mais que apresenta uma dimensão significativa e uma componente territorial privilegiada de contacto com o litoral.

\subsection{Metodologia de Análise}

A metodologia utilizada segue de perto o modelo proposto por Baptista e Silva (1989), que tem por objectivo estabelecer uma correspondência directa entre os custos de urbanização e o valor da taxa de urbanização. $\mathrm{O}$ modelo considerado entra em linha de conta com duas variáveis: i) os custos das infra-estruturas urbanísticas apresentados no Plano Plurianual de Investimentos e ii) a ocupação urbana prevista, medida através da população, para traduzir a maior ou menor capacidade de utilização das infra-estruturas urbanísticas.

O modelo utilizado é baseado em cinco fases sequenciais: i) a aquisição de informação geográfica de partida relevante para a definição do zonamento do território, ii) a georreferenciação das infra-estruturas urbanísticas; processamento da informação, determinação das respectivas áreas de influência, iii) zonamento do território, iv) determinação das perspectivas de ocupação urbana por zona, e v) determinação da TMU por zona (Figura 2).

$\mathrm{Na}$ fase 1 - aquisição e integração dos dados cartográficos - a produção de cartografia e a análise exploratória dos dados desenvolveram-se através do software ArcGIS 9.2. da

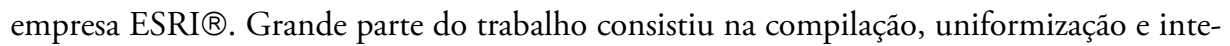
gração de informação geográfica já existente, a partir das plantas dos loteamentos existentes e as peças desenhadas dos projectos das infra-estruturas urbanísticas a executar. $\mathrm{Na}$ fase 2 - as infra-estruturas urbanísticas consideradas - decorrem do Plano Plurianual de Investimentos da Câmara Municipal de Aljezur, que foi formulado com base em estimativas orçamentais ou nos valores constantes nos projectos objecto de pedidos de financiamento comunitário. Conhecido o padrão espacial das infra-estruturas urbanísticas, determinou-se a sua incidência no território, em termos do montante de investimentos.

Estes podem ser diferenciados de acordo com duas categorias: os investimentos gerais que serão imputados a todo o concelho, não se perspectivando que produzam benefícios atribuíveis localmente a esta ou aquela zona e os investimentos locais que serão atribuídos a uma zona específica. Nesse sentido, foram definidas áreas de influência para os investimentos locais, de acordo com as unidades elementares de referenciaçáo do PDM: os limites dos aglomerados urbanos, respectivas áreas de expansão e os limites dos loteamentos. Na fase 3 - o zonamento do território - um dos pressupostos fundamentais deste modelo foi a diferenciaçáo espacial dos custos de urbanização, da qual resultou o zonamento do território. Para criar o zonamento foram utilizadas técnicas de análise espacial que permitiram o relacionamento de dados associados a diversas entidades geográficas.

Obedeceu a dois critérios: i) cada zona espelha um território beneficiado por um conjunto de infra-estruturas cuja incidência em termos do montante de custos é suficientemente distinta para a diferenciar de outra zona e ii) cada zona espelha um território, que reflecte um padrão de infraestruturação que se diferencia de outra zona, de tal forma que se possa esperar alguma estabilidade da sua definição ao longo do tempo. 
Figura 2 - Modelo de Cálculo da TMU.

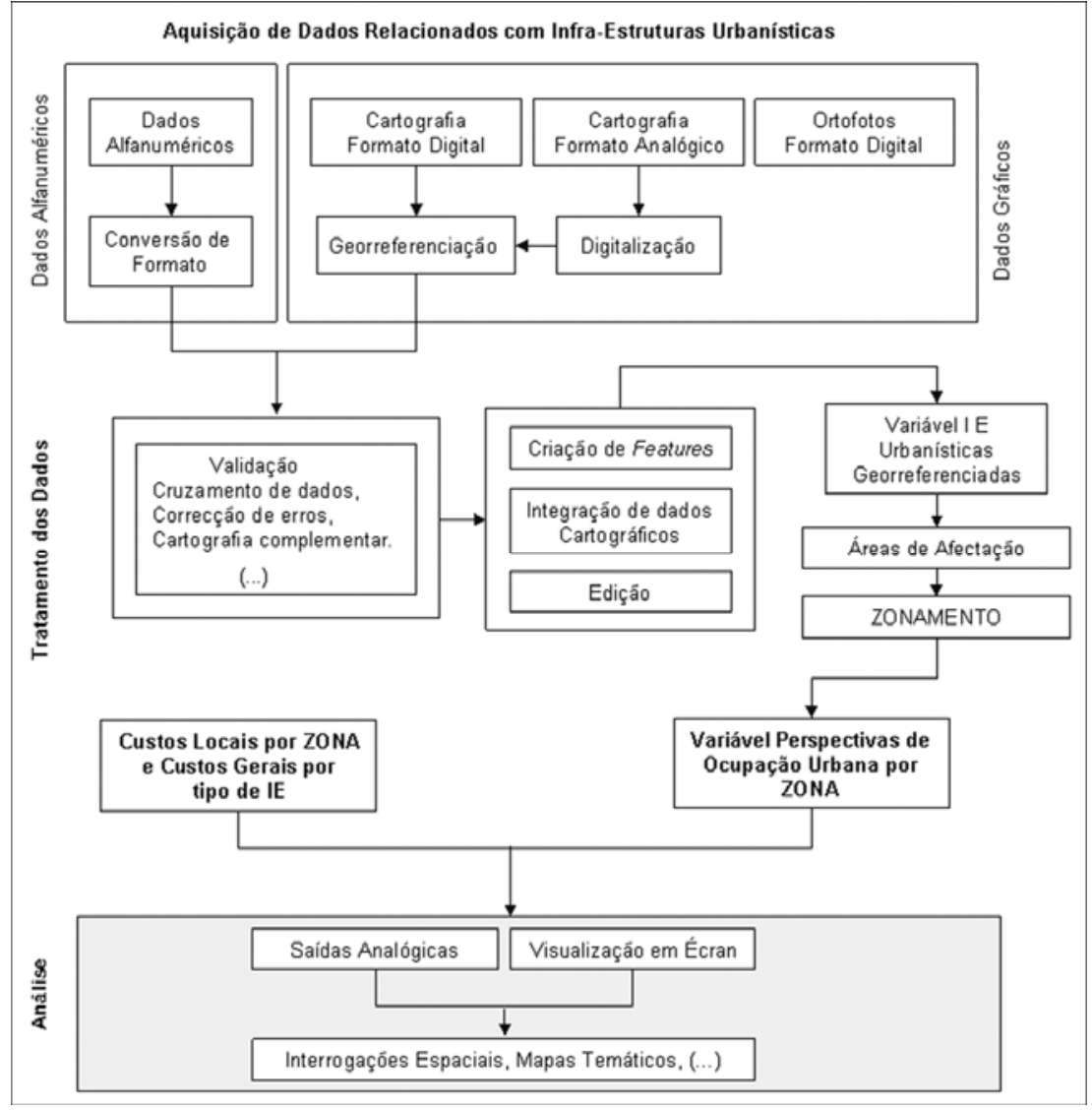

$\mathrm{Na}$ fase 4 - determinação das perspectivas de ocupação urbana - o período limite para que foram programados os investimentos foi o ano de 2011, tendo sido considerado um prazo aceitável, por parte dos serviços municipais, para a concretização do plano de investimentos. Embora se tenha adoptado um horizonte de cálculo para 2011 (cinco anos), Baptista e Silva (1989, pp. 114) refere que é conveniente seguir um horizonte de cálculo deslizante susceptível de revisóes bi-anuais. $\mathrm{O}$ indicador escolhido para traduzir a maior ou menor intensidade de utilização das infra-estruturas urbanísticas por zona, foi o ritmo de urbanização do concelho, através do ritmo de licenciamentos de área bruta de construção $(\mathrm{ABC})$, convertida pelo modelo em número de fogos e posteriormente em número de habitantes, recorrendo a uma capitação de área coberta de $120 \mathrm{~m}^{2}$, por cada 2,385 habitantes que compóem a família padrão do concelho. $\mathrm{Na}$ fase 5 - determinação da TMU por zona - a TMU é fixada para cada unidade territorial de acordo com a seguinte fórmula:

$$
T M U=\frac{\sum C I^{L}}{\sum \Delta P^{L} p^{L}}+\frac{\sum C I^{G}}{\sum \Delta P^{G} p^{G}}
$$


Sendo:

$\mathrm{CI}^{\mathrm{L}}$ os investimentos locais;

$\mathrm{CI}^{\mathrm{G}}$ os investimentos gerais;

Pop $^{\mathrm{L}}$ a população de cada zona beneficiada pelos CIL;

Pop $^{G}$ a população do concelho.

De referir duas situaçóes relevantes aquando da determinação dos investimentos: i) aos investimentos totais foram subtraídas as contribuiçóes comunitárias aprovadas e ii) devido à ausência de dados relativos aos custos de manutenção das infra-estruturas urbanísticas, foram aplicados os valores referidos no estudo Os Custos do Urbanismo (Carvalho 2002), a saber: $2 \%$ por ano, sobre o custo inicial das infra-estruturas. Determinados os custos de construção das infra-estruturas urbanísticas para o uso Habitação e tendo em conta o facto de náo se dispor de áreas de construção propostas por tipo de uso para o concelho de Aljezur, arbitraram-se os seguintes coeficientes: TMU Habitação = 1/2 TMU Indústria; TMU Comércio = TMU Serviços; TMU Comércio = 1,5 TMU Habitação.

\subsection{Desenvolvimento da Aplicação}

Numa política de transparência na incorporação de novas tecnologias no processo tributário, foi elaborada uma aplicação de apoio às tarefas diárias relacionadas com a aplicação da TMU e ao cruzamento da informação. Na concepção da aplicação foi utilizada a linguagem de programaçáo orientada a objectos que integra o ArcGIS: o Visual Basic for Aplications (VBA).

\subsubsection{Desenvolvimento de Interfaces Específicas}

Para a aplicação do algoritmo foram criadas três ferramentas de auxílio ao cálculo e gestão da TMU, a saber: i) interface para o cálculo da $\mathrm{TMU} / \mathrm{m}^{2}$ por tipo de uso, ii) interface de gestão dos dados relativos às infra-estruturas urbanísticas e iii) Interface de monitorização da TMU através da análise da evolução dos valores colectados.

A interface 1 tem como objectivo principal calcular a TMU por tipo de uso, tendo em conta a zona em que se insere. O programa ao processar informação espacial vectorial, permite gerar a $\mathrm{TMU} / \mathrm{m}^{2}$ tendo em conta as características de urbanização da zona, que foi previamente seleccionada no mapa pelo técnico. $\mathrm{Na}$ fase da obtençáo da taxa, no processo de licenciamento, quando o técnico insere os $\mathrm{m}^{2}$ de $\mathrm{ABC}$ a licenciar, por tipo de uso (e/ou número de fogos, no caso do tipo de uso Habitaçáo), o programa calcula a taxa e o respectivo somatório de $\mathrm{ABC}$ a licenciar. A interface 2 foi desenvolvida para gerir os dados relativos às infra-estruturas urbanísticas referentes a cada zona. Esta abordagem é fundamental, nomeadamente na perspectiva da permanente actualizaçáo dos dados cartográficos ou de infra-estruturas urbanísticas, explorando e mantendo adequado o valor do elevado investimento feito na sua aquisiçáo. A interface 3 tem como objectivo a monitorização da TMU através da análise da evolução, ao longo do tempo, dos valores colectados por zona. A monitorizaçáo da TMU deverá ser efectuada, no sentido de se conseguir um ajustamento e actualização da mesma, face à realização de medidas correctivas e prevençáo de situaçôes de desempenho insatisfatório. 


\section{RESUltados E CONSIDERAÇÓES FinAIS}

A aplicação do modelo à área do concelho de Aljezur permitiu definir um zonamento que espelha a política de afectação dos custos de infraestruturação aos beneficiados (Figura 3).

Figura 3 - Mapa com os valores da TMU/m² de construção.

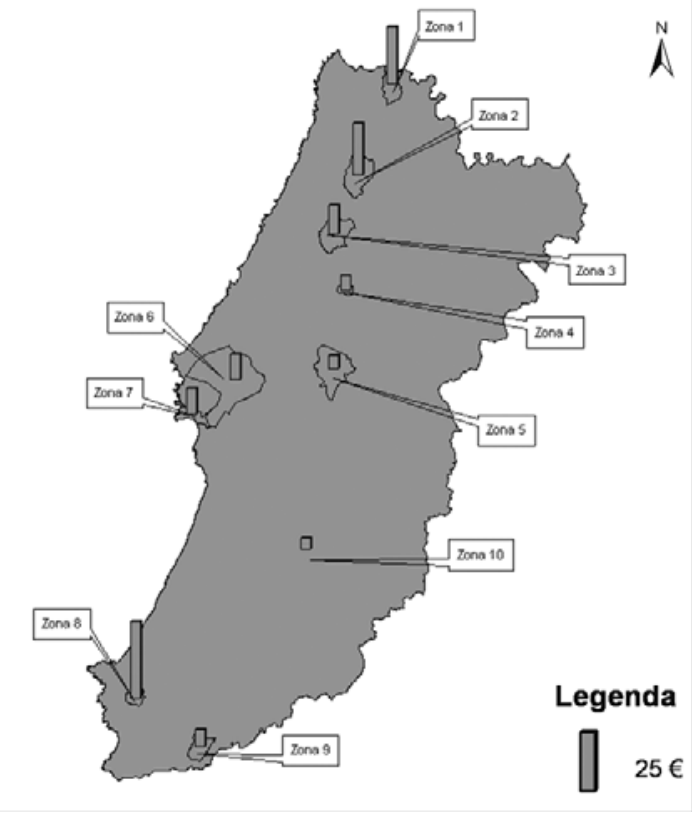

Da comparação entre as taxas em vigor e os encargos obtidos pelo modelo proposto (Quadro 1), conclui-se que os valores praticados actualmente são baixos, sobretudo se confrontados com as despesas que as novas urbanizaçóes e construções irão exigir ao município, ou ainda, se confrontados com as mais valias que as aprovaçóes urbanísticas conferem aos proprietários.

Quadro 1 - Análise comparativa das taxas decorrentes do actual regulamento e dos valores resultantes do modelo (encargos por $\mathrm{m}^{2} \mathrm{de} \mathrm{ABC}$ ).

\begin{tabular}{|c|c|c|c|c|c|c|}
\hline \multicolumn{2}{|c|}{ Regulamento actual } & \multicolumn{5}{|c|}{ TMU resultante da aplicação do Modelo } \\
\hline \multirow{2}{*}{ Espaços } & \multirow{2}{*}{ Encargos } & \multirow{2}{*}{ Zonas } & \multicolumn{4}{|c|}{ Encargos por Tipos de Uso } \\
\hline & & & Habitação & Comércio & Serviços & Indústria \\
\hline \multirow{4}{*}{ Urbanos } & & 1 & $36,14 €$ & $54,22 €$ & $54,22 €$ & $72,29 €$ \\
\hline & & 2 & $33,50 €$ & $50,25 €$ & $50,25 €$ & $67,00 €$ \\
\hline & $4,55 €$ & 3 & $18,44 €$ & $27,65 €$ & $27,65 €$ & $36,87 €$ \\
\hline & & 4 & $9,50 €$ & $14,25 €$ & $14,25 €$ & $19,00 €$ \\
\hline \multirow[t]{2}{*}{ Urbanizáveis } & $3,41 €$ & 5 & $8,33 €$ & $12,49 €$ & $12,49 €$ & $16,65 €$ \\
\hline & & 6 & $16,50 €$ & $24,74 €$ & $24,74 €$ & $32,99 €$ \\
\hline \multirow[t]{4}{*}{ Industriais } & $22,75 €$ & 7 & $16,63 €$ & $24,94 €$ & $24,94 €$ & $33,25 €$ \\
\hline & & 8 & $49,36 €$ & $74,04 €$ & $74,04 €$ & $98,72 €$ \\
\hline & & 9 & $11,10 €$ & $16,65 €$ & $16,65 €$ & $22,19 €$ \\
\hline & & 10 & $7.15 €$ & $10.72 €$ & $10.72 €$ & $14.29 €$ \\
\hline
\end{tabular}


As receitas municipais actuais provenientes da colecta da TMU são francamente escassas, não cobrem os investimentos programados e não correspondem assim à concretização das infra-estruturas propostas no Plano Plurianual de Investimentos pondo em causa o seu objectivo principal. O modelo proposto constitui um forte potencial para o reforço da capacidade financeira dos municípios, havendo toda a legitimidade e justificaçáo para o aumento das taxas praticadas.

Com o apoio da ferramenta desenvolvida pode-se realizar medidas correctivas, prevenir situaçóes de desempenho insatisfatório, reflectir no cálculo da TMU as novas necessidades em infra-estruturas urbanísticas e as alteraçóes nos investimentos e licenciamentos actuais e previstos. As vantagens para a autarquia com a implementação da aplicação elaborada com vista a incorporação de novas tecnologias no processo tributário são: i) fiabilidade da informação gerida, ii) melhoria significativa da qualidade e da natureza da informação, iii) abandono de tarefas executadas manualmente permitindo maior eficácia no funcionamento do serviço, iv) apoio na tomada de decisão e v) transparência no processo de definição da TMU.

\section{REFERÊNCIAS BIBLIOGRÁFICAS}

Baptista e Silva, J. 1989, A Criação de uma Taxa Municipal de Urbanização Espacialmente Diferenciada, Tese Mestrado em Planeamento Regional e Urbano, Universidade Técnica de Lisboa, Dezembro.

Baptista Lobo, C. 2006, Política de Solos e Tributação do Património Imobiliário, II Conferência do Ordenamento do Território e Revisão de PDM's, Planos Territoriais e Mercado Imobiliário, Covilhã, 25 e 26 de Outubro.

Carvalho, J. 2002, "Os Custos do Urbanismo", in O Sistema Financeiro e Fiscal do Urbanismo, Ciclo de Coloquios: O Direito do Urbanismo do Séc. XXI, Almedina, Setembro.

Correia, P. V. D. 2001, Políticas de Solos no Planeamento Municipal, 2.a ed., Serviço de Educação e Bolsas, Fundação Calouste Gulbenkian, Lisboa.

Sá, A. 2005, A Tributação da Propriedade Imobiliária como Instrumento de Política dos Solos, Dissertação para obtenção do Grau de Mestre em Urbanística e Gestão do Território, Universidade Técnica de Lisboa, IST, Agosto.

Moudon, A. \& Hubner, M. 2000, New Publication: Monitoring Land Supply with Geographic Information Systems, Land Lines, July, vol. 12, no 4.

Matos, J. 2001, Fundamentos de Informação Geográfica, 3. a ed., Lidel - Edições Técnicas, LDA, Março. 